March - 2010

\title{
Live, Online Short-Courses: A Case Study of Innovative Teacher Professional Development
}

\author{
Meghan E. Marrero, Karen A. Woodruff, and Glen S. Schuster \\ U.S. Satellite Laboratory Inc., USA \\ Jessica Fitzsimons Riccio \\ Teacher's College, Columbia University, USA
}

\begin{abstract}
Teachers are searching for new venues through which they may meet stringent professional development requirements. Under competitive funding from NASA's (National Aeronautics and Space Administration) Office of Education and the NASA Explorer Schools Project, U.S. Satellite Laboratory, Inc. created a series of live, online, interactive short-courses. In this case study, a mixed methods analysis of a variety of data sources reveals that diverse educators from a variety of classroom contexts view the short-courses as a useful professional development tool, both as a vehicle for a teacher's own professional growth and for classroom applications. Teachers were particularly interested in the ability to participate in a collaborative community of practice with other educators, instructors, and scientists from across the country, and they found the flexible design of the professional development to be useful. This short-course design offers promise for future professional development opportunities.
\end{abstract}

Keywords: Online learning; teacher professional development; in-service science teachers; synchronous online learning

\section{Background to the Study}

Traditional professional development for educators has been criticized for being irrelevant, ineffective, and fractured, and for not giving teachers what they actually need to teach students (Corcoran, 1995; Wilson \& Berne, 1999). The current educational culture of accountability has revamped the definition of teacher quality. In this culture of quality, teachers are largely responsible for their own professional development - often in order to maintain their state certification and their delineation as "highly qualified." For example, in New York State, professional certification is no longer granted for a lifetime; teachers must complete requisite hours of professional development within five-year cycles (New York State Education Department [NYSED], 2007). Faced with stringent content standards and high-stakes testing, 
teachers are turning to new and different sources for quality professional development. Many of them are looking to online sources (Garet, et al., 2001). In particular, teachers of science seek upto-date resources for professional development. Science is a dynamic and exciting field in which new information is constantly forthcoming; science educators need access to up-to-date research and curricular materials ready to be implemented in classrooms.

To that end, U.S. Satellite Laboratory, Inc. (U.S. Satellite), a small business focused on the design, development, and delivery of curriculum and professional development programs, sought to create online professional development opportunities that 1) were relevant to teachers' day-today practice, 2) provided an opportunity for professional sharing and collaboration, 3) contributed to teachers' professional growth, and, 4) were in a format accessible to a wide range of educators.

The short-courses, and therefore this study, were underpinned by a theoretical framework of social constructivism. In this framework, knowledge built by the learners is intertwined with their own world experiences and those shared with others. Social constructivism contends that knowledge is constructed as a group through interaction and knowledge-building. In social constructivism, "there are social aspects of the construction process; although individuals have to construct their own meaning...the process of constructing meaning always is embedded in a particular social setting of which the individual is a part” (Duit \& Treagust, 1998, p. 8). The teachers in this case study developed their scientific understanding and pedagogical content knowledge (PCK) (Shulman, 1986) through interactions with colleagues, NASA scientists, and teacher educators. Richardson (1997) notes in her discussion of social constructivism in teacher education, "It is within this interaction that cultural meanings are shared within the group, and then internalized by the individual” (p. 8). The design of the short-courses promoted constant discourse and collaborative knowledge-building among both participants and instructors. Participants brought their own sociocultural context to the dialogue and contributed to the understanding of others. Teachers were encouraged to share their own ideas and experiences; the instructors viewed these as important starting points for knowledge growth, as suggested by the professional development literature (van Driel, Beijaard, \& Verloop, 2001). The mutual growth and understanding is inherent when exploring the participants' perceptions of the short-courses. The case study methodology is also consistent with the constructionist epistemology and constructivist theoretical perspective in that it "will put all understandings, scientific and nonscientific alike, on the very same footing” (Crotty, 1998, p. 16). The goal of this study was to examine the educators' views on the efficacy of this professional development model.

\section{Methodology}

\section{Setting: The Live, Short-Courses for NASA Explorer Schools Program}

To address the professional development goals presented above, U.S. Satellite created a professional development program called "Live, Short-Courses for NASA Explorer Schools" under a competitive grant from NASA's (National Aeronautics and Space Administration) Office of Education and the NASA Explorer Schools (NES) initiative. NASA Explorer Schools are schools selected from across the United States to promote the use of NASA assets and 
educational content in classrooms. The U.S. Satellite professional development for NES educators consisted of seven short-courses, live (synchronous) online courses each comprising 46 one-hour sessions, with independent assignments as follow-up activities between sessions. Educators participated by simultaneously logging into an online classroom and using a telephone to dial into a conference call. This innovative format offered teachers the ability to take courses from home or school and to still interact live with expert instructors, guest research scientists, and other educators. The intent of the short-courses was to give educators an opportunity to actively learn content and applications for the classroom. Both the content and applications were to be incorporated within the teacher's curriculum in line with the professional development goal for the NES initiative, "to address local challenges in science, technology and mathematics education” (NASA, 2007).

Underpinned by the theories of social constructivism, the short-courses aimed to facilitate teachers' active learning, assimilation of activities into the classroom, and collaboration among groups, all of which have been shown to be factors that have the most significant impact on the professional growth of science and math teachers (Garet, et al., 2001; National Research Council, 1996). Guest scientific researchers from NASA, NOAA (the National Oceanographic and Atmospheric Administration), and other exemplary science institutions interacted with shortcourse participants and presented current research as it related to short-course content. A wide range of scientific topics was represented in the short-courses, including oceanography, meteorology, and heliophysics. A major goal was to improve teachers' pedagogical content knowledge (PCK) in science. PCK includes strong knowledge of the subject matter, or the content, but, more importantly, it includes knowledge of how this subject matter should best be taught to students. PCK includes, "the most powerful analogies, illustrations, examples, explanations, and demonstrations . . . that make it [the subject matter] comprehensible to others" and "an understanding of what makes the learning of specific topics easy or difficult" (Shulman, 1986, p. 9).

Each short-course began with introductions, and the participants soon realized that the unique online environment included educators from Florida to Nebraska, New York to Alaska. The fastpaced, interactive atmosphere of the short-course meant that each participant received an opportunity to ask and answer questions aloud and to share their unique, personal experiences. Additionally, instructors used embedded technological resources, such as online quizzes/polls, as a formative assessment and as a way for participants to share ideas quickly.

The participants were self-selected members of the NES community, including educators from active and alumni NES schools as well as from schools that had unsuccessfully applied to be an NES location. NES schools were given many professional development opportunities in different formats, online, onsite, and through travel. Other distance learning opportunities available to these educators included one-session webinars and events through NASA's DLN (digital learning network), a videoconferencing tool. Participants indicated that they had participated in many diverse professional development events within the NES network, and the lead members of the NES teams, all of whom were state certified, at each school were mandated to participate in professional development and were expected to encourage other teachers from their site to attend. 
For teachers who began short-courses with U.S. Satellite, the attrition rate was less than $1 \%$. Data for other NES activities is unavailable to the authors.

The short-course design was grounded in the research in online training; although, research in synchronous online design is sparse. Previous studies demonstrated online training to be as effective as in-person training and much more efficient and inexpensive (Schmeekle, 2003). Training sessions normally taught in person could be taught in one-half to two-thirds of the time using the online learning environment (Barker \& Brooks, 2005; Schmeekle, 2003). These studies, although they did not take place within teacher education, contributed to the compact design of the short-courses.

The live aspect of the short-course sessions was also deliberately designed to reflect research findings. In a classic study, Threlkeld and Brozoska (1994) found that support and interaction between students and instructors as well as between students are keys to success in distance learning environments. Carr-Chellman (2000) took this argument a step further to live contact, stating,

The advantages of synchronous interchanges include a more direct sense of collegial interaction, immediate resolution to questions posed, and possibly a strong contribution to the team building required to sustain future student interactions. The synchronous mode is particularly appropriate for the inclusion of motivating guest lectures in specific content areas. (p. 236)

Northrup (2000) highlighted the importance of the interaction between participants, explaining that it may mitigate feelings of isolation and frustration common in distance learning participants.

\section{Data Collection}

\section{Case Study Methodology}

We used a variety of data sources, including questionnaires, reflective essays, personal communications, and field notes to study the "bounded system” (Merriam, 1998) of participants in the NES short-courses. The case study is a methodology that provided us with the ability to examine the professional development as a whole, giving an in-depth look at the experience from multiple perspectives (Creswell, 2007; Merriam, 1998). Case studies rely primarily on qualitative methods, although quantitative data may be used to support emergent themes (Creswell, 2007).

\section{Questionnaires}

As a primary data source to study these short-courses as a professional development tool, the researchers administered an online mixed questionnaire to examine teacher views about the shared experience of the online short-courses. The mixed methods approach included open- 
ended questions embedded in a series of Likert and yes/no questions. The purpose of this design was to allow the researchers to gain a deeper understanding of teachers' feelings and impressions about the strengths and limitations of this approach to professional development while also collecting quantitative data to assess their general beliefs about the program's efficacy. The questionnaire was answered anonymously and questions were based on general program evaluation questions as put forth by NASA's office of Managements and Budgets. Both qualitative and quantitative sources of information gained were important; mixed methods design draws from the strengths of both qualitative and quantitative approaches (Creswell, 2003, Johnson \& Onwuegbuzie, 2004). Using mixed methods allowed the authors to support the qualitative data of the case study with additional information that could be quantified.

In 2007, educators who had participated in short-courses from November 2005 to March 2007 were invited to complete the online questionnaire concerning their experience. Respondents logged into the online survey system and answered fifteen questions, a mix of Likert-scale, yes/no, and open-ended items. Items were designed to discover information about the teachers' classroom context as well as how the short-courses contributed to their professional growth, whether the short-courses were relevant to local curricula, and whether they were able to use what they learned in their classrooms. Two of this study's authors were instructors in the short-courses under study and therefore took on the role of participant observers (Jorgensen, 1989).

\section{Reflective Essays}

A small percentage (approximately 10\%) of teachers participating in the live short-courses elected to take the course for graduate credit. Earned credits could be used by teachers toward earning/maintaining state certifications as well as for ascending district pay scales. Those teachers who earned credit completed additional projects based on classroom implementation of science content and pedagogical strategies learned in the short-course(s). These supplemental assignments included reflective essays, in which the educators critically examined their implementation of what they had learned. These essays served as a data source in this study.

While we cannot be certain, we believe that most teachers did not take advantage of the graduate credit opportunity for two reasons. First, these teachers were given many opportunities to earn credit through NES, often for simply attending workshops/events at their school; whereas, to earn credit for these courses, the educators were required to complete additional work beyond the course itself. Also, more of the teachers (approximately 20\%) earned continuing education units (CEU's), which did not require essay submissions yet are often accepted for teachers who wish to advance on the pay scale and/or to maintain state certification.

\section{Personal Communications}

Throughout the Live, Short-Courses program (2 years), U.S. Satellite team members remained in constant communication with participating educators, both during the courses as well as while teachers implemented what they had learned in the classroom. Team members, including scientists and teacher educators, were available by phone and email to discuss content, 
pedagogical strategies, and other issues. The nature of these communications varied but occurred quite often. Instructors often received several emails a week from participants. Field notes were recorded during this time and these notes as well as emails are an additional data source.

The use of diverse data sources provided triangulation for the themes that emerged in this study, which is considered to be a way to approximate validity in qualitative studies (Guba \& Lincoln, 1989). Additionally, these sources contributed to the rich, thick description (Merriam, 1998) of the case study within the Findings section.

\section{Data Analysis}

Data collected through the online survey tool were exported to a Microsoft Excel spreadsheet. Responses from the Likert and yes/no items were separated and percentages calculated for each response. To analyze the open-ended questions, the researchers followed the procedures of grounded theory analysis (Guba \& Lincoln, 1989). We first examined all of the data and made general notes of the results. Then data was broken into chunks for coding based on emerging categories or themes (open coding). Two of the researchers followed this independent procedure then peer-debriefed to agree on emergent themes (Creswell, 2003; Merriam, 1998). We then compared the themes across data sources and created categories (axial coding; Guba \& Lincoln, 1989). For example, one questionnaire response stated, "Interacting with teachers from a variety of locations was great!” During open coding, this response was categorized as interaction by both coders. In the axial coding process, the coders observed this theme across data sources and eventually determined that this was indeed an emergent theme, interaction with instructors, scientists and other educators.

After determining the emergent themes, each theme's frequency was calculated. This quantitative aspect of the study added another layer of validity; the numbers helped to justify the themes found, and "determine the distribution of a phenomenon within [the] chosen population" (Creswell, 2003, p. 216).

We followed the same procedure of open and axial coding, without quantifying results, to analyze the other data sources, including field notes, reflective essays, and personal communications. Then all data sources were considered together to build the case study.

\section{Findings}

\section{Quantitative Data}

\section{Demographics.}

Before delving into the results of the study, it is important to examine the demographics of the population of educators under study. Fifty-nine teachers (out of approximately 248 educators who participated in the Live, Short-Courses program) responded to the questionnaire, a response 
rate of almost 24\%. At least 13 respondents had participated in all seven possible short-courses. The respondents indicated that their schools represented a variety of demographic areas, including urban (41\%), suburban (19\%), rural (36\%), and other (4\%) (Figure 1).

How would you describe your school's location?

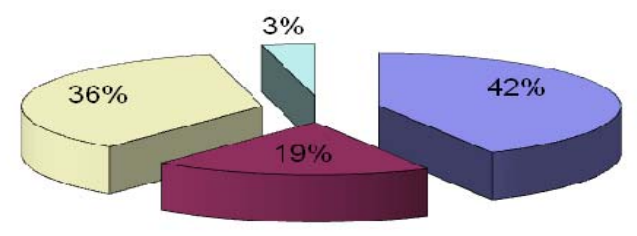

Figure 1. Location of schools.

The respondents teach pre-college grade levels from kindergarten through twelfth grade. Most taught within Grades 4 through 9, consistent with NES educator demographics. Forty percent of the participants reported teaching science subjects including physical science, earth science, general science, astronomy, biology, and environmental science. Other subject areas included health, physical education, gifted education, language arts, social studies, special education, mathematics, and reading. Respondents reported teaching students of a wide range of ability levels from students with emotional disturbance or learning disabilities to Advanced Placement courses. Five percent of respondents were informal educators.

\section{Relevance of Short-Courses}

The researchers were very interested in whether the participating educators felt that the shortcourses were relevant to their work at their schools. Regardless of their location or the myriad subjects taught, $79.6 \%$ of respondents reported that they were using what they learned in the short-course (content, activities, and strategies) during the current school year, and $96.6 \%$ of respondents anticipate using what they learned during the current school year. When asked who in their school community might benefit from participating in short-courses, 95\% chose other teachers, $51 \%$ chose parents, $44 \%$ chose paraprofessionals, and $34 \%$ chose administrators. One hundred percent of respondents would be interested in taking future short-courses.

When presented with the statement, "The content I learned in this course fits with my curriculum," 86\% chose "agree” or "strongly agree." The remaining participants chose "neutral." Respondents were also presented with the statement, "The Short-course(s) contributed to my professional growth.” In response, 78\% chose "strongly agree," 21\% chose "agree," and 1\% chose "neutral” (Figure 2). 


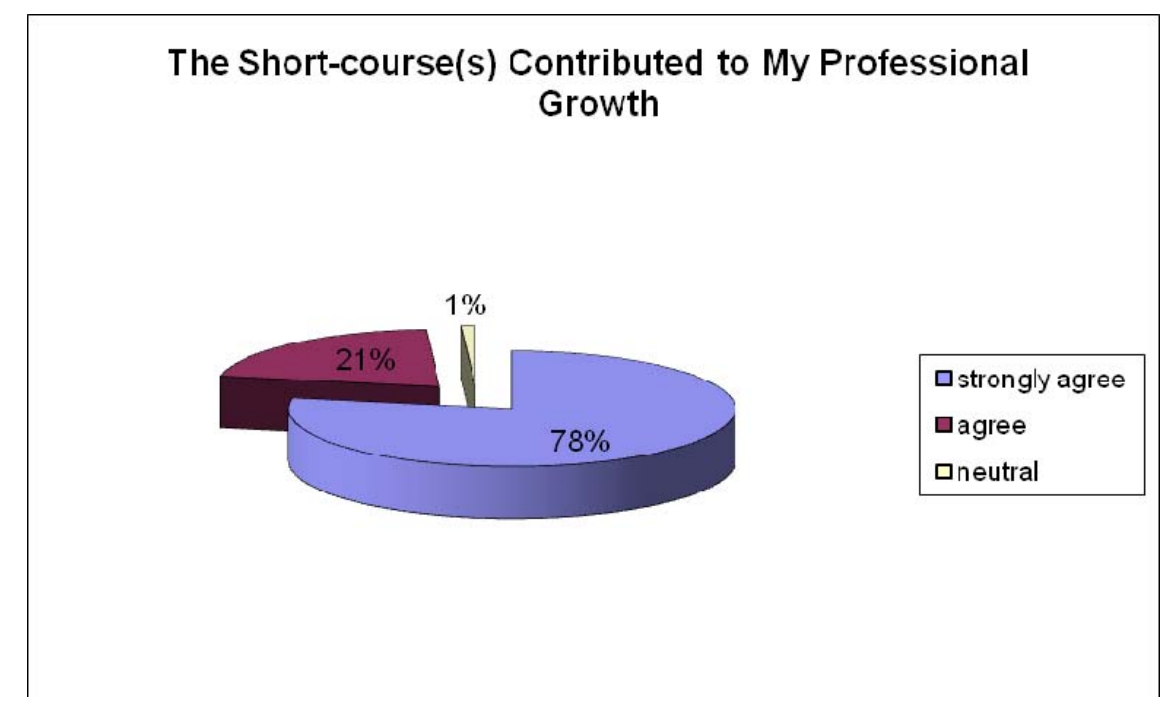

Figure 2. Contribution of the short-courses to professional development.

\section{Format of Short-Courses}

Because traditional online courses are held asynchronously, not live, and are self-paced, it was important to ask participants to compare their experience in this format with other online courses. Respondents were presented the statement, "I feel that a live, online course is a good model for professional development." Seventy-three percent chose "strongly agree,” 20\% chose "agree,” and 7\% chose "neutral" (Figure 3).

\section{I feel that a live, online course is a good model for} professional development.

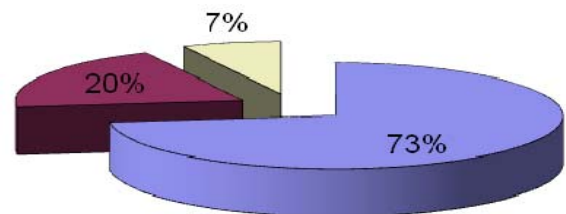

Figure 3.Short-courses as a good model for professional development.

Next, participants were presented with the statement, "I prefer live, online courses to online courses that are not live" (Figure 4). Fifty-four percent chose "strongly agree," 24\% "agree," 19\% "neutral," and 3\% “disagree." 


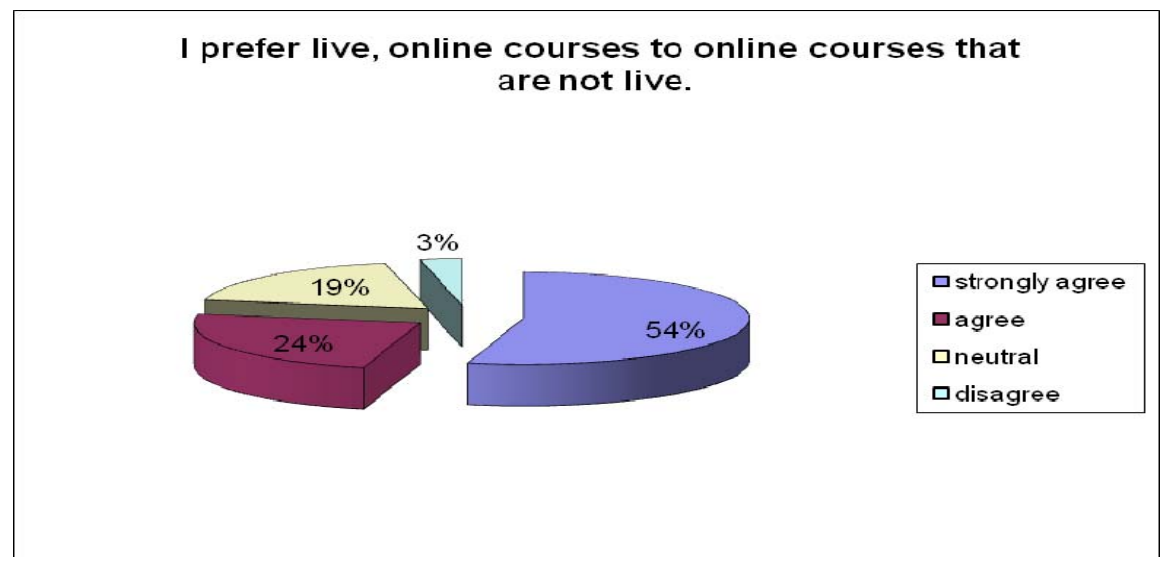

Figure 4. Preference for live online courses.

\section{Qualitative Data}

The final section of the questionnaire consisted of open-ended questions, intended to reveal some of the participants' specific attitudes and criticisms concerning the short-courses. Other qualitative data sources included subject-produced documents (i.e., reflective essays), field notes, and personal communications. Three major themes emerged from the qualitative sources: 1) interaction with other educators, 2) immediate feedback from instructors and scientists, and 3) flexibility of the course structure.

\section{Theme 1: Interaction with other educators.}

The most common theme (54\% of questionnaire respondents) was the ability to interact with, collaborate with, and gain knowledge from other educators. In addition to the questionnaire, this theme was evident in the reflective essays of participants as well as in the field notes. The fact that educators had the opportunity to interact and share across diverse contexts without traveling was a very positive feature of short-courses.

For instructors, it was noteworthy to observe the development of socially constructed knowledge building and of a professional network. At the first live session of participants, four to six logged onto the online classroom and called into the conference call about 10-15 minutes early for the one-hour class. The instructor typically made small talk, asking perfunctory questions about the weather or current events, although these brief interactions were punctuated by periods of science. By the second session, pre-class chatter was no longer facilitated by the instructor. Instead, teachers began sharing ideas, experiences, and strategies. They asked one another how they might incorporate what they had already learned and shared lessons into which new material could be incorporated. By the last class, the classmates were exchanging emails and the instructor needed to break through the animated conversation in order to begin class. 
The significance of this developing network of knowledge-sharing was also evident to the participants. Sample questionnaire responses centered on this theme included the following:

- Interacting with teachers from a variety of locations was great!

- [I enjoyed] professional interaction revolving around content.

- Being able to interact with other teachers from around the country

- I liked the live part for me because I could ask questions and communicate with others in the course.

- Collaboration with other teachers

Many individual educators felt that working with other diverse educators, sharing best practices, and discussing content in locations across the country were positive aspects of the short-courses. In her reflective essay, one teacher wrote,

The lessons were excellent and the live part was so important. I feel confident that I can implement them in my 5th grade class. Students will appreciate learning from ongoing interesting research. I also liked learning from other teachers across the country.

This teacher, like many others, viewed learning from other educators as an important aspect of her short-course experience. Similarly, another educator explained, "There were excellent applications of the subject matter . . .This is also an excellent venue for interacting with teachers nationwide.” The diverse group of educators - encompassing Grades K-12, myriad subjects from Advanced Placement Physics to kindergarten to physical education - felt that it was valuable to interact with and learn from one another in the live format.

Additionally, it was evident that through their interactions, the teachers were building knowledge together, reflecting the social constructivist theoretical framework. For example, in the course entitled Astro-Venture, which is based upon the NASA-developed curriculum module (accessible at http://astroventure.arc.nasa.gov/), each participant prepared a short presentation on content within the Astro-Venture curriculum guide. Content topics included the Doppler effect, calculating orbital eccentricity, and comparing tectonic activity on different planets. Several teachers remarked that these presentations allowed them to improve their understanding of these topics, both by presenting and by listening to and interacting with the other educators. For some of these teachers, the content was novel and seemed overwhelming, yet the friendly atmosphere of the short-course evidently assisted them in learning the topics.

\section{Theme 2: Immediate feedback from instructors and scientists.}

Another common theme, cited by $24 \%$ of questionnaire respondents, was the ability to receive immediate feedback to questions. In more common and traditional asynchronous online courses, students may post questions for a professor to be answered days later. During the live, shortcourse sessions, participants were highly encouraged to ask questions both of the instructors and 
of the guest scientists taking part in the class. The difference was that the answers were immediate and often resulted in reciprocal discussions.

During a typical class session, the instructor presented a PowerPoint presentation interspersed with live links, videos, animations, visualizations of scientific data, and much more. Along the way, participants were asked to try their hand at interpreting data, making predictions, and reflecting on new content. Brief poll questions were embedded throughout the lesson to check for understanding. Each short-course included a presentation by at least one guest speaker, such as a Mars volcanologist, oceanographer, astrobiologist, etc. These scientists presented current research in the field, enhancing the cutting-edge content of the courses. After the presentation, the educators often engaged in animated discussions with the guest, asking many questions and relating classroom applications.

The theme immediate feedback was very prevalent throughout the data sources as an important aspect of the short-courses. In their essays, teachers wrote, "I liked the live part for me because I could ask questions and communicate with others in the course," and "For me, the interaction with the presenters and the scientists they included in the short course was so important. I was able to ask questions and reflected on brand-new content." Another comment was, "I had a lot of questions and the immediate feedback was invaluable."

Questionnaire responses centered on this theme included, "being able to ask questions and discuss answers," "real-time interaction and feedback," "live questions were answered on the spot," and "immediate feedback and clarification to any question or misconception."

\section{Theme 3: Flexibility of course structure.}

In addition to the live interactivity and feedback, an emergent theme of course flexibility was often cited as an important positive aspect. For example, one questionnaire respondent wrote, "The fact that it was online gave me more flexibility. I'm a single mom and didn't have to seek child care to participate." Another respondent explained that "[the] short amount of time works better because of scheduling issues.”

The short-courses were held after school, in the evenings, or during the summer breaks in order to accommodate the busy schedules of educators. Teachers often shared that they liked being able to participate at night, after dinner and putting children to bed, or during the summer early in the morning. A session was normally offered twice in one day; participants were encouraged to attend the same session (i.e., 4 p.m. or 9 p.m. throughout a course), but having multiple sessions allowed changes if necessary. As noted by one teacher, "I really like the flexibility when they are offered more than one time per day because things come up at the last minute.”

\section{Limitations}

As we have mentioned, conducting live, synchronous online professional development for educators is a relatively new trend. Though we have employed this method over the 
implementation of several short-courses in several years, we look forward to the opportunity to provide several semesters of training in each of the short-courses so that as many teachers as possible can participate, and scenarios of implementation can be vetted.

A few questionnaire respondents (15\%) wished to see improvement in addressing technology issues. Examples included, "less distractions from teachers with technical problems," "setting up my computer for the course was challenging," "less technical difficulties that drag the speed of the course," and "eliminate technical difficulties."

The methods for data collection and analysis were limited by the researchers' ability to identify first-hand how participating educators implemented short-course content in their classrooms. In addition to self-reporting through Likert and yes/no questions, future data collection may include an interview process, whereby researchers visit and interview randomly selected teachers from each demographic, such as urban and rural, high-need, and affluent schools. Teachers could also provide evidence of student work to show how short-course content fit into their existing curriculum.

\section{Discussion and Implications}

Short-courses for NASA Explorer Schools primarily targeted Grades 4-9 science teachers, and the majority of participants teach science. However, representatives from other disciplines, including math, physical education, special education, social studies, language arts, and others, participated in short-courses. Intended implementation of curricular materials and use of content was effective across disciplines as $96.6 \%$ of study participants indicated that they anticipate using the materials during the same school year, which shows that the courses provided 'something for everyone.' Teachers in every discipline are responsible for maintaining a standard of excellence and completing professional development requirements. Short-courses provided educators with expert training and resources, which they may not have had access to through their local district. We are, however, unclear about how such diverse educators perceived that they benefitted from the courses themselves. This aspect of our findings certainly requires further study.

In addition, the short-courses promoted an environment where participants felt comfortable sharing ideas, reflecting on best practices, and interacting with instructors, scientific researchers, and practitioners. As this was the most common emergent theme, it is important to teachers to exchange information about using the resources in their classrooms, across diverse contexts. While they never met their classmates in person, it seems that the participants felt that the shortcourses offered the best of both worlds, live discussion with like-minded professionals across the country without having to travel. These findings affirm similar findings from research on asynchronous professional development experiences. Vrasidas and Zembylas (2004) used the lenses of social constructivism and situated cognition to examine online professional development. In the asynchronous programs under study, teachers were working on common tasks and activities and were monitored by moderators, and this design promoted interaction and the development of a sense of community among teachers. In a 2007 study, Hew and Hara examined the interactions of teachers within a listserv and found that teachers are often motivated 
by opportunities for knowledge sharing, but that face-to-face interactions often increase familiarity and therefore willingness to share knowledge. We wonder whether the synchronous interactions via telephone in the short-courses bred the same sort of increase in familiarity. Thus, our findings seem to refute the ideas asserted by Schlager and Fusco (2003) that online community development should be situated within local face-to-face teacher professional development communities, such as those that develop within local school districts. Our study shows that giving teachers a forum for sustained interaction might support the development of an online community of practice. Further study in this area is needed. Most of the respondents indicated that they preferred the live short-course format over the traditional asynchronous online course format. While it is possible that this result is due to participants' familiarity with the format, the researchers believe that the live format is particularly promising for professional development in science education as cutting-edge content can often be challenging. The synchronous course design allows participants to ask and receive answers, clarifying questions on the spot, thus eliminating some of the frustrations that may be the result of learning difficult content.

While these findings are promising, the next step would be to examine changes in the teachers' content knowledge as well as their in pedagogical content knowledge (PCK) to see if there are any resulting changes in teaching practice. The results of this study are nevertheless important because in order for professional development to be effective, teachers must 'buy in' to the model and what they are learning.

\section{Conclusion}

Increasing numbers of educators are seeking online sources to meet their professional development needs. This mixed methods study examined the views of teachers from NASA Explorer Schools about the viability of the live, online short-course model for professional development. Findings indicate that the teachers felt it was an effective model. Emergent themes indicate that teachers felt it was important to interact with and learn from other educators who are located across the country. Also, the live nature of the courses was critical in terms of working through new science concepts and ideas because teachers were able to receive immediate feedback from instructors and participating scientists. Of course, the online design also offered flexibility that traditional professional development workshops do not. The response to this online community of reflective educators includes positive professional growth and overwhelming enthusiasm for participants to continue to use short-courses as a solution for meeting their professional development needs. 


\section{References}

Barker, B., \& Brooks, D. (2005). An evaluation of short-term distributed online learning events. International Journal on Elearning, 4(2), 209-228.

Carr-Chellman, A.(2000). The ideal online course. British Journal of Educational Technology, 31(3), 229.

Creswell, J. W. (2003). Research design: Qualitative, quantitative, and mixed methods approaches $\left(2^{\text {nd }}\right.$ ed). Thousand Oaks: Sage.

Corcoran, T.B. (1995). Helping teachers teach well: Transforming professional development. CPRE Policy Briefs. Retrieved from http://www.ed.gov/pubs/CPRE/t61/index.html

Crotty, M. (1998). Introduction: The research process. In The foundations of social research: Meaning and perspective in the research process. Thousand Oaks: Sage.

Duit, R., \& Treagust, D. (1998). Learning in science: From behaviorism towards social constructivism and beyond. In B. J. Fraser \& K. G. Tobin (Eds.), International handbook of science education (pp. 3-25). Great Britian: Kluwer Academic Publishers.

Garet, M.S., Porter, A.C., Desimone, L., Birman, B.F., Yoon, K. S. (2001). What makes professional development effective? Results from a national sample of teachers. American Educational Research Journal, 38(4), 915-945.

Guba, E. G., \& Lincoln, Y. S. (1989). Judging the quality of fourth generation evaluation. In Fourth generation evaluation (pp. 228-251). Thousand Oaks: Sage.

Johnson, R. B., \& Onwuegbuzie, A.J. (2004). Mixed methods research: A research paradigm whose time has come. Educational Researcher, 33(7), 14-26.

Jorgensen, D. L. (1989). Participant observation: A methodology for human studies (Vol. 15). Thousand Oaks, CA: Sage.

Merriam, S. B. (1998). Qualitative research and case study applications in education. Hoboken, NJ: Jossey-Bass.

NASA Explorer Schools. (2007). Retrieved from http://explorerschools.nasa.gov/portal/site/nes/

National Research Council (NRC). (1996). National science education standards. Washington, DC: National Academy Press.

New York State Education Department (NYSED) (2007). Types of certificates and licenses. Retrieved from http://www.highered.nysed.gov/tcert/certificate/typesofcerts.htm 
Northrup, P.T. (2001). A framework for designing interactivity into web-based instruction. Educational Technology, 41(2), 31-39.

O’Loughlin, M. (1992). Rethinking science education: Beyond Piagetian constructivism toward a sociocultural model of teaching and tearning. Journal of Research in Science Teaching, 29(8), 791-820.

Richardson, V. (Ed.) (1997). Constructivist teacher education: Building new understandings. New York: Routeledge.

Schlager, M. S., \& Fusco, J. (2003). Teacher professional development, technology, and communities of practice: Are we putting the cart before the horse? The Information Society, 19, 203-220.

Schmeeckler, J.M. (2003). Online training: An evaluation of the effectiveness and efficiency of training law enforcement personnel over the internet. Journal of Science Education and Technology, 12(3).

Shulman, L. S. (1986). Those who understand: Knowledge growth in teaching. Educational Researcher, 15(2), 4-14.

Threlkeld, R., \& Brzoska, K. (1994). Research in distance education. In B. Willis (Ed.), Distance education: Strategies and tools. Englewood Cliffs, NJ: Educations Technology Publications, Inc.

Van Driel, J.H., Beijaard, D., \& Verloop, N. (2001). Professional development and reform in science education: The role of teachers' practical knowledge. Journal of Research in Science Teaching, 38(2), 137- 158.

Vrasidas, C., \& Zembylas, M. (2004). Online professional development: Lessons from the field. Education \& Training, 46(6/7), 326-334.

Willis, B. (Ed.) (1993). Distance education: Strategies and tools. Englewood Cliffs, NJ: Educations Technology Publications, Inc.

Wilson, S.M, \& Berne, J. (1999). Teacher learning and the acquisition of professional knowledge: An examination of research on contemporary professional development. Review of Research in Education, 24, 173-209.

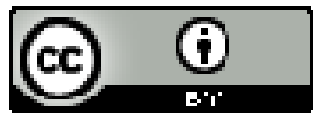

